\title{
Effectiveness Of Polyethylene Cover Versus Polyethylene Cover With Artificial Tear Drop To Prevent Dry Eye In Critically III Patients: A Randomized Controlled Clinical Trial
}

This article was published in the following Dove Press journal: Clinical Ophthalmology

Tahereh Nikseresht ${ }^{\prime}$

Alireza $\mathrm{Abdi}^{2}$

Alireza Khatony $\mathbb{( D}^{3}$

'Student Research Committee, Kermanshah University of Medical Sciences, Kermanshah, Iran; ${ }^{2}$ Clinical Research Development Center, Imam Reza Hospital, Kermanshah University of Medical Sciences, Kermanshah, Iran; ${ }^{3}$ Health Institute, Social Development and Health Promotion Research Center, Kermanshah University of Medical Sciences, Kermanshah, Iran
Correspondence: Alireza Khatony Clinical Research Development Center Imam Reza Hospital, Nurse Blvd.,

Kermanshah, Iran

Tel/fax +98 8338279394

Email Akhatony@gmail.com
Purpose: To compare the effectiveness of polyethylene cover versus polyethylene cover with artificial tear drop to prevent dry eye in critically ill patients.

Methods: In this clinical trial, 208 patients were randomly assigned into two groups of polyethylene cover, and polyethylene cover with artificial tear drop. In each of the two groups, one eye was randomly selected as a control eye and the other was considered as an intervention eye. In the polyethylene cover group, the eye was covered with polyethylene. In the polyethylene cover and artificial tear drop group, an artificial tear drop was applied every $8 \mathrm{hrs}$ to the eye, and then it was covered with polyethylene. The control eye received the routine intensive care unit eye care (washing the inside of the eye and the eyelids with distilled water). In both groups, the eyes were examined for eye dryness by an ophthalmologist for 5 days.

Results: The incidence of dry eye after the use of both polyethylene cover and polyethylene cover with artificial tear drop methods was lower than that of a conventional method. Both methods of polyethylene covering and polyethylene covering with artificial tear drop were effective, but clinically, the method of polyethylene cover with artificial tear drop was more effective.

Conclusion: Both methods of polyethylene covering and polyethylene covering with artificial tear drop were more effective than a conventional method, but the method of polyethylene cover with artificial tear drop was clinically more effective. Therefore, it is recommended for use in critically ill patients.

Keywords: artificial tear drop, dry eye, intensive care unit, polyethylene cover, prevention

\section{Introduction}

In the intensive care unit (ICU), patients are often very ill, and changes in their level of consciousness affect their natural ocular surface defense mechanisms. ${ }^{1}$ Eye care is one of the important aspects of care for ICU patients, which is usually neglected. ${ }^{2}$ In $75 \%$ of patients under heavy sedation, the incomplete closure of the eyelids causes dryness of the eye surface. ${ }^{3,4}$ Also in ICU patients, mechanical ventilation with positive pressure causes fluid imbalance that leads to conjunctival edema, which is one of the causes of incomplete closure of the eyelids and ocular problems. Evidence suggests that $60 \%$ of intubated ICU patients are at risk of eye surface injury such as dry eye disease, due to incomplete closure of the eyelids. ${ }^{5}$ Dry eye disease is a multifactorial condition caused by loss of tear film hemostasis. ${ }^{6}$ 
Different care is available to prevent the onset of ocular complications in intubated patients under mechanical ventilation. These include the use of methylcellulose drop, ophthalmic ointment, closing of eyelids by adhesive tape, and use of eye patches or polyethylene cover. ${ }^{7}$

Several studies have examined the effects of various eye care methods in preventing eye injuries, but their results are contradictory and controversial. In this regard, one study compared the effects of two methods of lubricating drops and polyethylene cover on preventing eye injuries in patients whose blink reflux was reduced or lost. The results indicated that, the use of polyethylene cover was more effective. ${ }^{8}$ In another study, the effect of combined use of Hypromellose drop and Lacri-lube, and polyethylene cover in prevention of corneal epithelial damage in ICU patients was compared, and results showed the similar effects of both methods. ${ }^{9}$ In another study, the effects of two methods of lanolin ointment and polyethylene cover on prevention of corneal abrasion in patients admitted to the ICU were compared with each other, and the results showed similar effects of both methods in preventing corneal abrasion. ${ }^{10}$ Another study compared the effects of carbomer dye drop and polyethylene cover on the prevention of dry eye, and the results showed a more effective role of polyethylene cover in this regard. ${ }^{11}$ Despite the existence of various eye-care protocols for the prevention of ocular complications in ICU patients, studies are still not sufficient in this regard. ${ }^{12,13}$

Because dry eye is very common in ICU patients and may lead to more serious complications such as corneal perforation, scleritis, and endophthalmitis, ${ }^{14,15}$ and considering the contradictory results of existing studies, the authors of this study decided to examine the effects of "polyethylene cover" and "polyethylene cover with artificial tear drop" on the prevention of dry eye in critically ill patients.

\section{Materials And Methods Study Design}

This study was a single-blind randomized clinical trial which was conducted from July 2016 to May 2017, and was based on the CONSORT guideline.

\section{Study Hypothesis}

The research hypothesis was: both methods of "polyethylene cover" and "polyethylene cover with artificial tear drop" are more effective in preventing dry eye than the conventional method.

\section{Sample And Sampling Method}

The statistical population consisted of all patients admitted to the ICUs of educational hospitals in the city of Ilam, Iran. The sample size was determined to be 208 individuals with a confidence level of $95 \%$ and power of $80 \%$ using the studies of Cortese and Koroloff., ${ }^{8,9}$ The participants were selected by convenience method and were randomly allocated into one of the two groups of "polyethylene cover," and "polyethylene cover with artificial tear drop" by lottery. The number of participants in each group was 52 and in each participant, one eye was considered as the control eye and the other eye was considered as the intervention eye. In each participant, each eye was randomly selected as the intervention eye or the control eye using a table of random numbers. Inclusion criteria included being 18 years old or above, having a GCS of 8 or less, absence of trauma on the face and head, lack of corneal dryness and abrasion (approved by ophthalmologist), having no history of eye diseases, having no history of using ophthalmic lubricants (before hospitalization), having no history of hospitalization in ICU during the past month, being intubated and connected to the ventilator, being in ICU for more than $24 \mathrm{hrs}$, incomplete closure of the eyelids due to the use of anesthetic-sedation drugs, having negative results of Schirmer and fluorescein tests during the study, and giving a written and informed consent through the first-degree relatives (parents or legal guardian of the patient) for participation in the study. Patients were excluded from the study in case of death, transfer to other wards, tracheal extubation, increased consciousness, and return of the blink reflexes.

\section{Measurement Instruments}

The data-collection tool was a two-part questionnaire. The first part contained 15 questions about demographic characteristics, type of disease, duration of hospitalization, GCS score, use or non-use of anesthetic-sedative drugs, duration and amount of anesthetic-sedation drugs, and amount of peak inspiratory pressure (PIP) and positive end expiratory pressure (PEEP).

The second part of the questionnaire was related to the results of Schirmer and fluorescein tests. The graded sterile stripes with the brand name of SM Tube, made in Japan, were used. To perform the fluorescein test, the sterile fluorescein stain stripes were manufactured by 
Iranian company Elham Teb, and the HSL150 hand-held Slit Lamp, manufactured in Germany, were used. The polyethylene covers used in this study were paper sterile stripes made by Pars Atlas Company in Iran. Also, the artificial tear drops, brand name Tearlose, were made by Sina Darou Company in Iran.

\section{Interventions}

At first, the study permission was obtained from the Kermanshah University of Medical Sciences (KUMS) deputy for research and technology, and then, the researcher attended the ICUs of Imam Khomeini and Shahid Mostafa Khomeini Educational Hospitals of Ilam and visited the eligible patients. The conditions of all eligible patients were examined at the beginning of the study by an ophthalmologist for eye dryness and corneal abrasions.

For examination of eye dryness, Schirmer graded stripes were used as follows to diagnose dryness: the tip of the strip was situated at the edge of lower eyelid and if the strip became moist less than $5 \mathrm{~mm}$, it represented eye dryness. If the strip became moist for $5 \mathrm{~mm}$ or more, it was considered as lack of eye dryness. After confirming the lack of eye dryness, fluorescein staining was used to examine corneal abrasion. For this purpose, a sterile tape with a fluorescein orange-colored substance on one side was slowly rubbed against the inner edge of the lower eyelid, and the eyelid was opened and closed several times to spread the color on the eye surface. Then, with the help of fluorescein staining blue light, the cornea was examined by an ophthalmologist. The areas with abrasions in the cornea became green under the blue light of the slit lamp.

After confirming the absence of corneal abrasion, the samples were randomly allocated into two groups of "polyethylene cover" and "polyethylene cover with artificial eye drop" ( $n=52$ for each group). In each group, one eye was considered as the "control eye" and the other was considered as the "intervention eye." Selection of the eyes as control or intervention was done randomly using a table of random numbers. In the "polyethylene cover" group, a coverage was applied from the top of the eyebrow to the cheekbone prominence, and its surrounding was fixed by an anti-allergy adhesive tape. In the "polyethylene cover with artificial tear drop," an artificial tear drop was placed in the lower eyelid of the intervention eye by the researcher every $8 \mathrm{hrs}$, and then the polyethylene cover was applied from the top of the eyebrow to the cheekbone prominence, and was fixed by an anti-allergy adhesive tape. In both groups, the polyethylene cover was replaced by the researcher on a daily basis, or if it was removed from the surface of the skin, ruptured or contaminated. The "control eyes" received the routine ICU eye care by the researcher, which included washing the inside of the eye and the eyelids with distilled water and then drying them with sterile gauze. The duration of intervention was five days. During this period, the "intervention" and "control" eyes in both groups were examined daily for eye dryness by an optometrist in the evening shift, and the results were recorded in the relevant forms. It should be noted that, if before the end of the 5-day period, the blink reflex returned, the subject became alert or was extubated, he/she had to be excluded from the study (Figure 1).

\section{Data Analysis}

Data were analyzed by the Statistical Package for the Social Sciences (SPSS V.18.0; SPSS Inc., Chicago, IL, USA) using descriptive (simple and relative frequency, mean, and standard deviation) and analytical statistics (Kolmogorov-Smirnov test, independent $t$-test, Friedman test, Fischer's exact test and Mann-Whitney $U$-test). At first, the normality of data was assessed using the Kolmogorov-Smirnov test. Non-parametric tests were used to analyze the data because all the variables except age had an abnormal distribution. Independent $t$-test was used to compare the mean age of the two groups. Friedman test was used to assess the dry eye status in each control and intervention eye during 5 days of the study. Fischer's exact test was used to compare the level of eye dryness between the intervention and control eyes in each of the study groups. Also, the Mann-Whitney $U$-test was used to compare the eye dryness between the intervention eyes in the two groups of "polyethylene cover" and" polyethylene cover with artificial tear drop." The significance level was set at 0.05 .

\section{Ethical Considerations}

This trial was conducted in accordance with the Declaration of Helsinki. The Ethics Committee of the University approved the study with the code: 1395.177.KUMS.REC. The study with code IRCT201506294736N8 was registered at the Clinical Trials Center of Iran. In the current study, all subjects were unconscious and intubated, so a written informed consent was obtained from the first-degree relatives of subjects (parents or their legal guardians) and they were assured about the confidentiality of their personal data and patient information. 


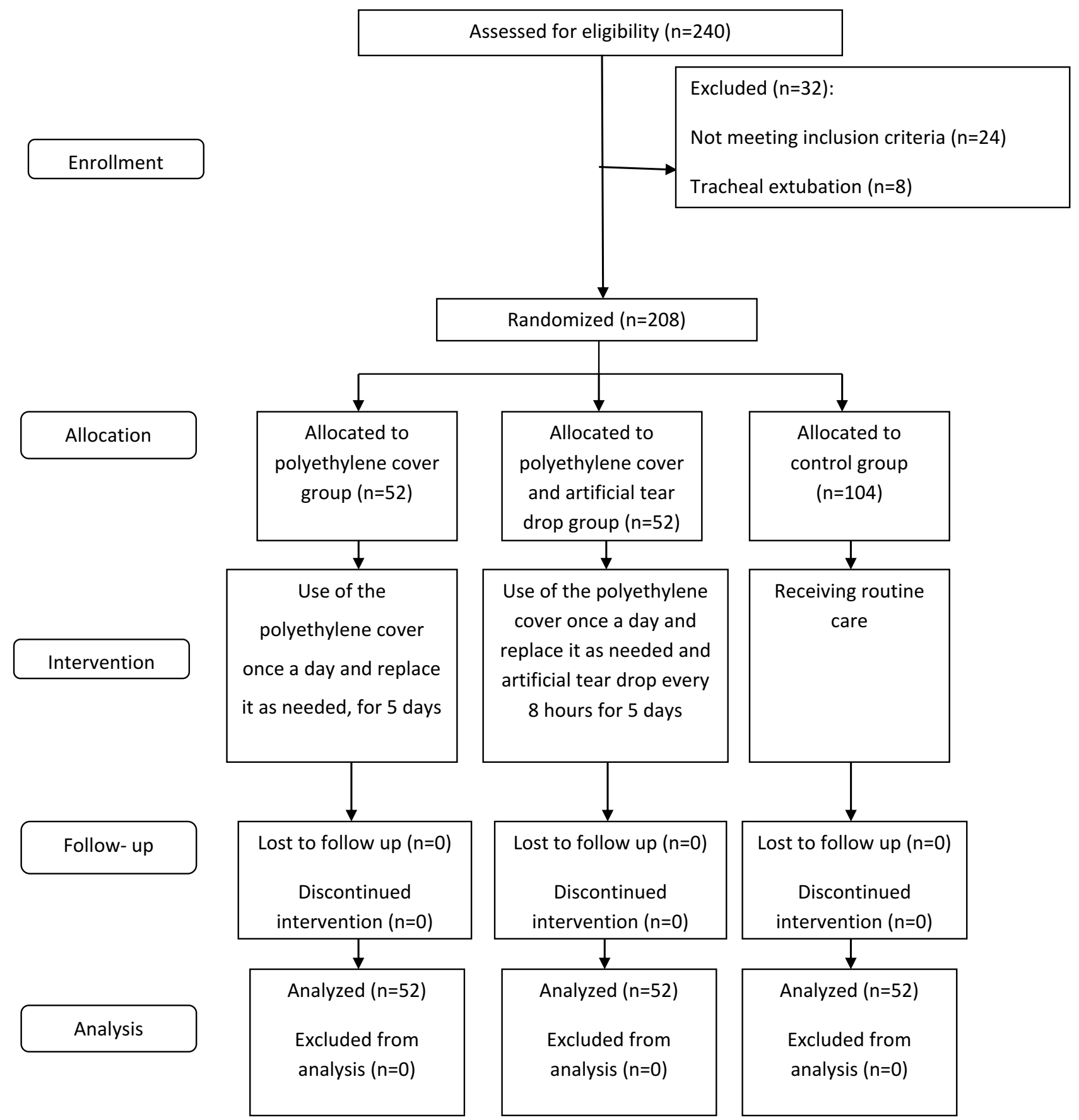

Figure I CONSORT diagram of study process.

\section{Results}

Of the 104 subjects, 75 were men ( $72 \%$ ) and 29 were female (28\%). Their mean hospital stay in the ICU was $10 \pm 3$ days. The mean age of the subjects in the groups of "polyethylene cover" and "polyethylene cover with artificial tear drop" was $53 \pm 20.5$ and $51.3 \pm 19.7$ years, respectively. No statistically significant difference was found between the two groups in terms of demographic characteristics and confounder variables, including type of disease, duration of hospitalization,
GCS score, use or non-use of anesthetic-sedative drugs, duration and amount of anesthetic-sedative drugs, and amount of PIP and PEEP (Table 1).

In the "polyethylene cover" group, the incidence of eye dryness in the intervention eye was statistically different at different days of the study ( $p<0.001)$. In the first, second, and third days, none of the subjects developed eye dryness, but on the fourth day, five eyes $(10 \%)$ and on the fifth day, 16 eyes (30\%) out of 52 eyes developed eye dryness. 
Table I Demographic Characteristics Of Participants In Each Of The Study Groups

\begin{tabular}{|c|c|c|c|}
\hline Variables & $\begin{array}{l}\text { Polyethylene } \\
\text { Cover }(n=52)\end{array}$ & $\begin{array}{l}\text { Polyethylene Cover And } \\
\text { Artificial Tear Drop }(n=52)\end{array}$ & $p$-value \\
\hline Age (mean $\pm S D)$ & $53.01 \pm 20$ & $51 \pm 19$ & NS* \\
\hline Sex (male: female) & $38: 14$ & $37: 15$ & NS \\
\hline Marital status (single: married) & $39: 13$ & $34: 18$ & NS \\
\hline ICU length of stay (mean $\pm S D$ ) & $10 \pm 3$ & $9 \pm 2$ & NS \\
\hline Glasgow Coma Scale (mean \pm SD) & $5.2 \pm 1$ & $6 \pm 1$ & NS \\
\hline Days of sedation (mean $\pm \mathrm{SD}$ ) & $0 \pm 1$ & $1 \pm 1$ & NS \\
\hline Use of sedation (\% of subjects) & 42 & 57 & NS \\
\hline $\mathrm{PIP}^{\dagger}($ mean $\pm \mathrm{SD})$ & $21.2 \pm 4.82$ & $22 \pm 5.42$ & NS \\
\hline $\operatorname{PEEP}^{\ddagger}($ mean $\pm \mathrm{D})$ & $5 \pm 1$ & $5.4 \pm 0.8 \mathrm{I}$ & NS \\
\hline
\end{tabular}

Notes: ${ }^{*}$ Non-significant. ${ }^{\dagger}$ Peak inspiratory pressure. ${ }^{\ddagger}$ Positive end expiratory pressure.

There was a significant difference between the control eyes in terms of dry eye incidence at different days of the study $(p<0.001)$. The occurrence of dry eye in this group was increasing, so that on the first day, none of the subjects had dry eye and on the second, third, and fourth days of the study, 4 (7\%), $22(47 \%)$, and $35(67 \%)$ eyes developed eye dryness, respectively. Most of the dry eye cases were recorded on the fifth day of the study, on which 46 of 52 eyes (88\%) developed eye dryness. On the fourth day of the study, there was a statistically significant difference in the polyethylene cover group between the intervention and control eyes $(p<0.001)$ in terms of dry eye incidence, but on other days this difference was not significant. In other words, on the fourth day of the study, the use of polyethylene cover was more effective than "conventional care" in preventing dry eye (Table 2).
In the group of "polyethylene cover with artificial tear drop," the incidence of eye dryness in the intervention eyes was statistically different at different days of the study ( $p<0.001$ ), so that on the first, second, and third days, none of the subjects had dry eye, but on the fourth day, two eyes (4\%) and on the fifth day, 16 eyes (30\%) out of 52 eyes developed eye dryness. In the control eye group, there was a statistically significant difference between the incidence of dry eye at different days of the study $(p<0.001)$. The occurrence of dry eye in this group was increasing, so that on the first day, none of the samples had dry eye and on the second, third, and fourth days of the study, 3 (6\%), 17 (33\%), and 29 (55\%) eyes were suffering from eye dryness. Most of the dry eye cases were related to the fifth day of the study, on which 46 of 52 eyes (88\%) developed eye dryness.

Table 2 Comparison Of The Level Of Eye Dryness In The Intervention And Control Eyes In Each Group From The First To Fifth Day Of The Study

\begin{tabular}{|c|c|c|c|c|c|c|c|}
\hline \multirow[t]{2}{*}{ Study Days } & \multirow[t]{2}{*}{ Schirmer Score } & \multicolumn{2}{|c|}{ Polyethylene Cover } & \multirow[t]{2}{*}{$p$-value } & \multicolumn{2}{|c|}{ Polyethylene Cover And Artificial Tear Drop } & \multirow[t]{2}{*}{$p$-value } \\
\hline & & $\begin{array}{l}\text { Control } \\
\text { n (\%) }\end{array}$ & $\begin{array}{l}\text { Intervention } \\
\text { n (\%) }\end{array}$ & & $\begin{array}{l}\text { Control } \\
\text { n (\%) }\end{array}$ & $\begin{array}{l}\text { Intervention } \\
\text { n (\%) }\end{array}$ & \\
\hline First & $\begin{array}{l}<5 \mathrm{~mm}^{\mathrm{a}} \\
\geq 5 \mathrm{~mm}^{\mathrm{b}}\end{array}$ & $\begin{array}{l}0(0) \\
52(100)\end{array}$ & $\begin{array}{l}0(0) \\
52(100)\end{array}$ & $N / A^{c}$ & $\begin{array}{l}0(0) \\
52(100)\end{array}$ & $\begin{array}{l}0(0) \\
52(100)\end{array}$ & N/A \\
\hline Second & $\begin{array}{l}<5 \mathrm{~mm} \\
\geq 5 \mathrm{~mm}\end{array}$ & $\begin{array}{l}4(7) \\
48(92)\end{array}$ & $\begin{array}{l}0(0) \\
52(100)\end{array}$ & $\mathrm{N} / \mathrm{A}$ & $\begin{array}{l}3(5.8) \\
49(94.2)\end{array}$ & $\begin{array}{l}0(0) \\
52(100)\end{array}$ & N/A \\
\hline Third & $\begin{array}{l}<5 \mathrm{~mm} \\
\geq 5 \mathrm{~mm}\end{array}$ & $\begin{array}{l}22(47) \\
30(57)\end{array}$ & $\begin{array}{l}0(0) \\
52(100)\end{array}$ & $\mathrm{N} / \mathrm{A}$ & $\begin{array}{l}17(32.7) \\
35(67.3)\end{array}$ & $\begin{array}{l}0(0) \\
52(100)\end{array}$ & $\mathrm{N} / \mathrm{A}$ \\
\hline Fourth & $\begin{array}{l}<5 \mathrm{~mm} \\
\geq 5 \mathrm{~mm}\end{array}$ & $\begin{array}{l}35(67) \\
17(32)\end{array}$ & $\begin{array}{l}5(10) \\
47(90)\end{array}$ & $<0.001$ & $\begin{array}{l}29(55) \\
23(44)\end{array}$ & $\begin{array}{l}2(4) \\
50(96)\end{array}$ & $<0.001$ \\
\hline Fifth & $\begin{array}{l}<5 \mathrm{~mm} \\
\geq 5 \mathrm{~mm}\end{array}$ & $\begin{array}{l}46(88) \\
6(12)\end{array}$ & $\begin{array}{l}16(30) \\
36(70)\end{array}$ & $N S^{d}$ & $\begin{array}{l}46(88) \\
6(12)\end{array}$ & $\begin{array}{l}16(30) \\
36(70)\end{array}$ & $<0.001$ \\
\hline
\end{tabular}

Notes: ${ }^{a} \mathrm{~A}$ value of less than $5 \mathrm{~mm}$ indicates eye dryness. ${ }^{\mathrm{b}} \mathrm{A}$ value of equal or more than $5 \mathrm{~mm}$ indicates absence of eye dryness. ${ }^{\mathrm{C}} \mathrm{N} / \mathrm{A}$ : Not applicable. ${ }^{\mathrm{d}} \mathrm{NS}$ : Non-significant. 
In the "polyethylene cover with artificial tear drop" group, there was a statistically significant difference in the incidence of eye dryness between the intervention and control eyes on the fourth and fifth days $(p<0.001)$. On the fourth day, $55 \%$ of the samples in the control group and $4 \%$ of the subjects in the intervention group suffered from dry eye. On the fifth day, the control eyes of $88 \%$ of the subjects developed eye dryness, while in the intervention eyes, only $30 \%$ of the Schirmer tests was positive (Table 2).

In the first, second, third, and fifth days of the study, there was no statistically significant difference between the two groups of "polyethylene cover" and "polyethylene cover with artificial tear drop" in terms of eye dryness. However, on the fourth day, this difference was statistically significant $(p<0.001)$ (Table 3 ).

\section{Discussion}

The aim of this study was to compare the effects of two methods of "polyethylene cover" and "polyethylene cover with artificial tear drop" on the prevention of dry eye in critically ill patients. In our study, both methods of "polyethylene cover" and "polyethylene cover with artificial tear drop" were more effective in preventing eye dryness than conventional methods. The method of "polyethylene cover with artificial tear drop" was clinically more effective than the use of polyethylene cover alone. Several studies have been carried out on the effects of different eye care methods in the prevention of dry eye, but their results were contradictory. In this regard, one study compared the effects of two methods of polyethylene cover and carbomer drop on prevention of dry eye in patients admitted to ICU, and the results showed that polyethylene cover was more effective than the other method. ${ }^{11}$ Our results are in line with this study in indicating the effectiveness of the "close chamber" method in reducing the

Table 3 Comparison Of Eye Dryness Between The Two Groups From The First To Fifth Day Of The Study

\begin{tabular}{|l|l|l|l|}
\hline $\begin{array}{l}\text { Study } \\
\text { Days }\end{array}$ & $\begin{array}{l}\text { Polyethylene } \\
\text { Cover (Mean } \\
\text { Rank) }\end{array}$ & $\begin{array}{l}\text { Polyethylene Cover And } \\
\text { Artificial Tear Drop } \\
\text { (Mean Rank) }\end{array}$ & $p$-value \\
\hline First & 52 & 52 & NS* \\
Second & 52 & 52 & NS \\
Third & 52 & 52 & NS \\
Fourth & 54 & 51 & $<0.001$ \\
Fifth & 56 & 48 & NS \\
\hline
\end{tabular}

Note: *Non-significant. level of eye dryness. In another clinical trial, the effect of "polyethylene cover" and "viscotears gel" on the prevention of corneal injury in patients admitted to the ICU was compared and the results showed that both methods had the same effect on the prevention of corneal injury. ${ }^{14}$ In the above study, the effects of two methods of close chamber (polyethylene cover) and open moist chamber (viscotears gel) have been compared, but in our study, two methods of close chamber (polyethylene cover) and open moist chamber (polyethylene cover with artificial tear drop) have been compared together. The results of our study showed that the "closed moist chamber" method was more clinically effective than the "close chamber" method. In another study, the effects of three methods of artificial tear drop, moist chamber, and polyethylene cover on prevention of corneal injury in patients admitted to the ICU were investigated. The results showed that polyethylene cover and moist chamber were more effective than artificial tear drops and had similar effect on dry eye prevention. ${ }^{16}$ Our results are in line with this study, as both studies indicate that the use of a close chamber method is more effective than an open chamber method in preventing eye injuries. They both can help the eye surface to stay moist for longer periods of time.

In one study, the effects of two methods of moist chamber and vitamin A ophthalmic ointment on the prevention of dry eye and corneal abrasion in ICU patients were compared and the results indicated that vitamin A ointment was more effective. ${ }^{15}$ Our results contradict the findings of this study. In this study, two methods of open and close chamber have been compared, while in our study, two close chamber methods were compared together. In the above study, the open chamber method (ointment) was more effective than the close chamber method, but in our study, both close chamber methods were similarly effective in preventing the eye injuries. In another study, the effects of two methods of ophthalmic lubricants and hydrogel dressings on the prevention of keratopathy in patients admitted to the ICU were compared, and the results revealed similar effects of both methods. ${ }^{17}$ In this study, the effects of two methods of open chamber (ophthalmic lubricant) and close chamber (hydrogel dressing) were compared and the results showed similar effects of both methods, while in our study, two types of close chambers were compared and the results indicated that "close moist chamber" method was clinically more effective. In a clinical trial, the effects of four methods of eye care, including the use of adhesive tape, 
antibiotic ointment, artificial tear drop, and ophthalmic lubricant ointment on the prevention of eye injury in patients under general anesthetic were compared. The results showed similar effects of three methods of adhesive tape, antibiotic ointment, and ophthalmic lubricant in preventing eye and corneal injuries. This is why, in the artificial tear drop group, eye injury was significantly higher than the other three groups. ${ }^{18}$ In the above study, all of the methods used for eye care were open chamber, but in our study two close chamber methods were used and compared. In our study, due to the simultaneous use of artificial tear drop and polyethylene cover, the chance of eye injury was significantly reduced. The reason for this reduction could be due to the combined effects of artificial tear drop and polyethylene cover in keeping the moisture in the eye. The polyethylene cover prevents exposure of the eye surface to the environment and acts as a protective barrier to help prevent tear evaporation from the surface of the eye, which helps maintain the stability of the lacrimal film. In another study, the use of two methods of open chamber (ophthalmic lubrication with adhesive tape) and close chamber (swimming glasses) in preventing corneal injury in patients under general or semi-anesthesia were compared. The results showed that the close chamber method was more effective than the open chamber method. ${ }^{19}$ Our results are in line with this study. In the above study, the close chamber method was more effective in preventing eye injury than the open chamber method. In our study, the use of the close chamber methods "polyethylene cover" and "polyethylene cover with artificial tear drop" was more effective than the use of the open chamber method in the control group. In another research, three methods of polyethylene cover, liposic ointment, and artificial tear were compared for prevention of keratopathy. One eye of each patient was considered as intervention group and the other as control. The results indicate that polyethylene is more effective in preventing keratopathy than other methods. ${ }^{20}$ Consistent with this study, our results also revealed that the closed chamber method is more effective in preventive eye injury than the open chamber method. In a single-blind clinical trial, the effect of normal saline on the incidence of keratopathy was investigated. For this purpose, the patient's eyes were randomly assigned to one of the two control and intervention groups. The intervention group received standard care plus normal saline, but the control group received only standard care including simple eye ointment, artificial tears, and eye patching. The results showed that routine care is more effective than routine and normal saline in preventing eye surface damage. ${ }^{21}$ In the above-mentioned study, two open chamber methods were compared, but in the present study, the effect of two closed chamber methods was compared with the open chamber method in the prevention of ocular surface damage, in which the close chamber method was more effective. According to the results of the aforementioned studies as well as our study, it can be argued that in ICU patients whose immune mechanisms are impaired, the use of a close chamber combined with ophthalmic lubricants can play a significant role in preventing eye dryness and injuries by creating a moist chamber.

We encountered several limitations in our study. The duration of study was only five days for each subject, which given the facilities that we had, did not allow an extended period of intervention. In our study, there was no age limit for the entry of subjects to the study, which had a potential to affect our results due to differences in the physical conditions of subjects at different ages. Because most of the subjects in our study had head trauma and intracranial hemorrhage, and had undergone brain surgeries, they had to be monitored and examined regularly for pupil reflexes, and this interfered with the use of the polyethylene cover as it had to be removed during the ocular examination. After the examination the cover was replaced. Another limitation of our study was the changes in dosage of anesthetic-sedative drugs, which reduced the duration of mechanical ventilation use and the patient's stay in ICU. If this happened before the end of the study, the subject was excluded from the study and was replaced by a new subject. In the present study, the role of medications on dry eye was not investigated, although the effect of this factor can be moderately controlled due to the random allocation of subjects to study groups. Also, it is notable we compared the efficacy of three methods; therefore, we tried to reveal the best way for preventing dry eye disease among the mentioned approaches.

\section{Conclusion}

Both methods of "polyethylene covering" and "polyethylene covering with artificial tear drop" were more effective than the conventional method (washing the inside of the eye and the eyelids with distilled water and then drying with sterile gauze), but the method of "polyethylene cover with artificial tear drop" was clinically more effective. Therefore, the use of the combined method of "polyethylene cover with artificial tear drop" is recommended for 
eye care in critically ill patients. The present study was conducted on subjects under mechanical ventilation, who mostly had traumatic and non-traumatic brain damage, thus similar studies are recommended in other patients. Our study was without age limits, so similar studies are recommended to be conducted on subjects with a specific and limited age range. The duration of our study was five days; therefore, similar studies with a longer intervention period are recommended.

\section{Availability Of Data And Materials}

Data and material are available by contacting the corresponding author. Data can be shared for up to one year after the article is published. In order to access the raw data, it is necessary to obtain the permission of the University Research Vice-Chancellor.

\section{Disclosure}

The authors report no conflicts of interest in this work.

\section{References}

1. Marshall AP, Elliott R, Rolls K, et al. Eyecare in the critically ill: clinical practice guideline. Aust Crit Care. 2008;21(2):97-109. doi:10.1016/j.aucc.2007.10.002

2. Dawson D. Development of a new eye care guideline for critically ill patients. Intensive Crit Care Nurs. 2005;21(2):119-122. doi:10.1016/j. iccn.2005.01.004

3. Ramirez F, Ibarra S, Varon J, Tang R. The neglected eye: ophthalmological issue in the intensive care unite. Crit Care Shock. 2008;11 (3):73.

4. Sy A, O'Brien KS, Liu MP, et al. Expert opinion in the management of aqueous Deficient Dry Eye Disease (DED). BMC Ophthalmol. 2015;15(1):133. doi:10.1186/s12886-015-0122-z

5. McHugh J, Alexander P, Kalhoro A, et al. Screening for ocular surface disease in the intensive care unit. Eye. 2008;22(12):1465. doi:10.1038/ sj.eye. 6702930

6. Craig JP, Nichols KK, Akpek EK, et al. TFOS DEWS II definition and classification report. Ocular Surf. 2017;15(3):276-283. doi:10.1016/j. jtos.2017.05.008

7. Lenart SB, Garrity JA. Eye care for patients receiving neuromuscular blocking agents or propofol during mechanical ventilation. Am J Crit Care. 2000;9(3):188.
8. Cortese D, Capp L, McKinley S. Moisture chamber versus lubrication for the prevention of corneal epithelial breakdown. Am J Crit Care. 1995;4(6):425-428.

9. Koroloff N, Boots R, Lipman J, Thomas P, Rickard C, Coyer F. Randomised controlled study of the efficacy of hypromellose and lacri-lube combination versus polyethylene/cling wrap to prevent corneal epithelial breakdown in the semiconscious intensive care patient. Intensive Care Med. 2004;30(6):1122-1123. doi:10.1007/ s00134-004-2203-y

10. So HM, Lee CCH, Yan WW, et al. Comparing the effectiveness of polyethylene covers (Gladwrap) with lanolin (Duratears) eye ointment to prevent corneal abrasions in critically ill patients: a randomized controlled study. Int J Nurs Stud. 2008;45:1566.

11. Kocaçal Güler E, Eşer İ, Eğrilmez S. Effectiveness of polyethylene covers versus carbomer drops (Viscotears ${ }^{\circledR}$ ) to prevent dry eye syndrome in the critically ill. J Clin Nurs. 2011;20(13-14):19161922. doi:10.1111/j.1365-2702.2010.03559.x

12. Sorce LR, Hamilton SM, Gauvreau K, et al. Preventing corneal abrasions in critically ill children receiving neuromuscular blockade: a randomized, controlled trial. Pediatr Crit Care Med. 2009;10 (2):171-175. doi:10.1097/PCC.0b013e3181956ccf

13. Zhou Y, Liu J, Cui Y, et al. Moisture chamber versus lubrication for corneal protection in critically ill patients: a meta-analysis. Cornea. 2014;33(11):1179-1185. doi:10.1097/ICO.0000000000000224

14. Kousha O, Kousha Z, Paddle J. Exposure keratopathy: incidence, risk factors and impact of protocolised care on exposure keratopathy in critically ill adults. J Crit Care. 2018;44:413-418. doi:10.1016/j. jerc.2017.11.031

15. Babamohamadi H, Nobahar M, Razi J, et al. Comparing vitamin A and moist chamber in preventing ocular surface disorders. Clin Nurs Res. 2018;27(6):714-729. doi:10.1177/1054773817695618

16. Shan H, Min D. Prevention of exposure keratopathy in intensive care unit. Int J Ophthalmol Clin Res. 2010;3(4):346.

17. Ezra DG, Chan MPY, Solebo L, et al. Randomised trial comparing ocular lubricants and polyacrylamide hydrogel dressings in the prevention of exposure keratopathy in the critically ill. Intensive Care Med. 2009;35(3):455. doi:10.1007/s00134-008-1284-4

18. Kocatürk Ö, Kocatürk T, Kaan N, Dayanır V. The comparison of four different methods of perioperative eye protection under general anesthesia in prone position. J Clin Anal Med. 2012;3(2):163-165. doi:10.4328/JCAM.607

19. Sivasankar S, Jasper S, Simon S, et al. Eye care in ICU. Indian J Crit Care Med. 2006;10(1):11-14. doi:10.4103/0972-5229.24683

20. Kalhori RP, Ehsani S, Daneshgar F, Ashtarian H, Rezaei M. Different nursing care methods for prevention of keratopathy among intensive care unit patients. Global J Health Sci. 2016;8(7):212. doi:10.5539/ gjhs.v8n7p212

21. Davoodabady Z, Rezaei K, Rezaei R. The impact of normal saline on the incidence of exposure keratopathy in patients hospitalized in intensive care units. Iran J Nurs Midwifery Res. 2018;23(1):57. doi:10.4103/ijnmr.IJNMR_187_16
Clinical Ophthalmology

\section{Publish your work in this journal}

Clinical Ophthalmology is an international, peer-reviewed journal covering all subspecialties within ophthalmology. Key topics include: Optometry; Visual science; Pharmacology and drug therapy in eye diseases; Basic Sciences; Primary and Secondary eye care; Patient Safety and Quality of Care Improvements. This journal is indexed on PubMed

\section{Dovepress}

Central and CAS, and is the official journal of The Society of Clinical Ophthalmology (SCO). The manuscript management system is completely online and includes a very quick and fair peer-review system, which is all easy to use. Visit http://www.dovepress.com/ testimonials.php to read real quotes from published authors. 